\title{
Digital photogrammetry as a tool for virtual reconstruction of lost architectures: elevations and three-dimensional models of masonry and brick constructions
}

\author{
M. Cabeza Gonzalez \& A. Soler Estrela \\ Universidad Jaume I, Spain
}

\begin{abstract}
Interest in architectural heritage conservation arises from the need to preserve the cultural memory of the society to which it belongs. However, many examples have been lost over the course of history, and we currently only have brief written summaries of their existence or, at best, a few remains of historic buildings in ruins.

Due to the lack of original documentation on these constructions, most of the resources are devoted to on-site data collection to ensure virtual models are as faithful to the originals as possible. Advances in digital photography have placed photogrammetric methods at the forefront of data collection systems. The images taken offer extensive information, making these methods ideal for the study of architectural remains from masonry buildings, where factors such as colour and texture of the remains are determining factors in reconstruction processes.

This paper details how to undertake accurate architectural surveys for this type of case, using photogrammetric restitution techniques and low-cost devices such as conventional digital cameras to generate elevations and three-dimensional models with photo-realistic textures, and high accuracy for these types of survey. Keywords: masonry, data collection, photogrammetry.
\end{abstract}

\section{Introduction}

Brick and stone are materials common to most of our architectural heritage. Interventions which depend on the conservation state and any other available information on the construction are essential to ensuring preservation. 
In this way, the deterioration of these architectures over the years has led to the disappearance or, at best, ruin of many significant examples. In such cases, previous studies acquire special graphical and historical importance, as it is obvious that without such baseline data it would not be possible to draw up reasonable proposals for intervention on constructions in order to repair, restitute or rebuild them.

Following criteria respecting architectural heritage, understood as a material document to be preserved, a number of methodologies and studies appear aiming at a thorough study and identification of the values of monuments.

For Gothic architecture, it is possible to go as far back as Viollet-le-Duc [1], author of the exceptional Reasoned Dictionary.

In this kind of construction, the most suitable on-site data collection methods are indirect measurement systems. In order to implement these it is necessary to recognise architectural features, although overall it is difficult to take direct measurements for this kind of construction.

In addition, non-intrusive methods allow us to work without altering the object of study. In buildings of great historical interest like those studied, this is not just an advantage, but rather a necessary requirement.

Currently, laser technology and photogrammetry are used to produce extremely precise and efficient architectural surveys. Thanks to the millions of points obtained, it is possible to generate a virtual three-dimensional model of the object for analysis.

\section{Area of practice: current preserved condition}

The Palace of Centelles, built in the second half of the fifteenth century, was situated at the top of the village, on the outskirts, opposite the church of Santa Maria la Mayor. One of the important personalities who lodged there was King Felipe III, who stayed at the palace at the time of his wedding to Margaret of Austria in Valencia in 1599 (ACCRS [2]).

However, after the death of Magdalena of Centelles in 1596, the palace was no longer used as a permanent residence and a long process of deterioration, leading to its final destruction, began, even though it was declared a National Monument in 1920. This was not only due to the lack of maintenance, but also to subsequent sales and divisions of the property from the late nineteenth century, resulting in its conversion into humble family homes and the consequent fragmentation of the palace.

Currently, only the remains of three towers of the wall which surrounded the palace represent this past existence, as most of the ruins preserved can be regarded as archaeological remains of abandoned homes, many of which are in clear danger of collapse. The owners of these homes remodelled and adapted them to their needs, and as a result the elements that once shaped the palace deteriorated badly or disappeared completely.

In fact, most of the information available to us is provided by Danish architects Egil Fischer and Vilhelm Lauritzen who compiled a comprehensive description of the palace in its days of splendour (Muller [3]). 


\section{Methodology}

The state of ruin in most of the palace makes access dangerous, so it was decided to use photogrammetry as the on-site data collection system, making it possible to execute a comprehensive survey of the different elements using a simple digital camera, easier to carry than the heavy equipment of other indirect measurement systems such as laser scanners.

Photogrammetry from multiple pictures is the most accurate, powerful and robust solution. This method is based on the adjustment in block of multiple images and can be adapted to any kind of camera, regardless of the format. There are no geometric restrictions for the object under study. In addition, even if the camera is not calibrated, it can be calibrated during the external orientation process of the images (Lerma García [4]).

There is the additional possibility of generating digital models once images have been spatially-oriented. After a filtering process, a digital model adapted to point clouds obtained by correspondence techniques is generated, adding texture to the high resolution model from the existing colour information found in the original images. This means that 3D photo-realistic models of the highest quality can be created.

It should be noted that the size of these models does not correspond to reality, so it is advisable to take some relevant measurements of accessible elements using direct measurement systems such as the flexometer and laser distance meter, which allow us to adjust the scale of the results.

The work follows three steps:

\section{Planning \\ 2. Data collection \\ 3. Data processing}

\subsection{Planning}

This first step, prior to fieldwork, lets us determine the correct position and number of shots necessary. It is especially important to take weather and time of day into account for this system, as light is the main issue when taking photographs (Almagro Gorbea [5]).

It should be noted that the results depend on how pictures are linked, so it is necessary to take photographs of each area from at least three different locations and there should be a large overlap between images.

Due to advances in photogrammetry software for processing pictures, camera calibration is no longer a relevant factor for the subsequent data processing, although it is true that it will always be positive for the final results.

\subsection{Data collection}

Data collection is carried out using a 10.2 MP digital Nikon D-80 camera, with an 18-135 lens and aperture of f/3.5-5.6. The pictures are used to support direct readings of different building elements as well as photogrammetric processes. 
Table 1: Features of camera used.

\begin{tabular}{|l|l|}
\hline Camera & Nikon D-80 \\
\hline Image Sensor & RGB CCD 23.6X15.8 mm - 10.75 million total pixels \\
\hline Sensitivity & 100 to 1600 (ISO equivalent) \\
\hline Exposure metering & $\begin{array}{l}\text { 3D Colour Matrix Metering II }- \text { Centre-Weighted - Spot } \\
\text { Metering }\end{array}$ \\
\hline
\end{tabular}

Table 2: Picture characteristics.

\begin{tabular}{|c|c|c|c|c|}
\hline Camera & Aperture & Focal length & Sensitivity & Shutter speed \\
\hline Nikon D-80 & F/5 & $18 \mathrm{~mm}$ & ISO100 & 2.5 seconds \\
\hline
\end{tabular}

This data collection system is therefore determined by the location and number of pictures, as well as their resolution. The necessary continuity between the different photographs taken from each studied element is ensured by the correct positioning of the camera and by taking a sufficient number of photographs.

To ensure accurate data collection, between shots camera location must be moved about 0.2 times the distance from the object. For example, if the camera is placed $3.5 \mathrm{~m}$ from the photographed object, the distance between a camera location and the next should be about $0.7 \mathrm{~m}$, equivalent to one step approximately. Therefore, the shorter the distance from the object, the more pictures must be taken to record the geometry of the element in greater detail.

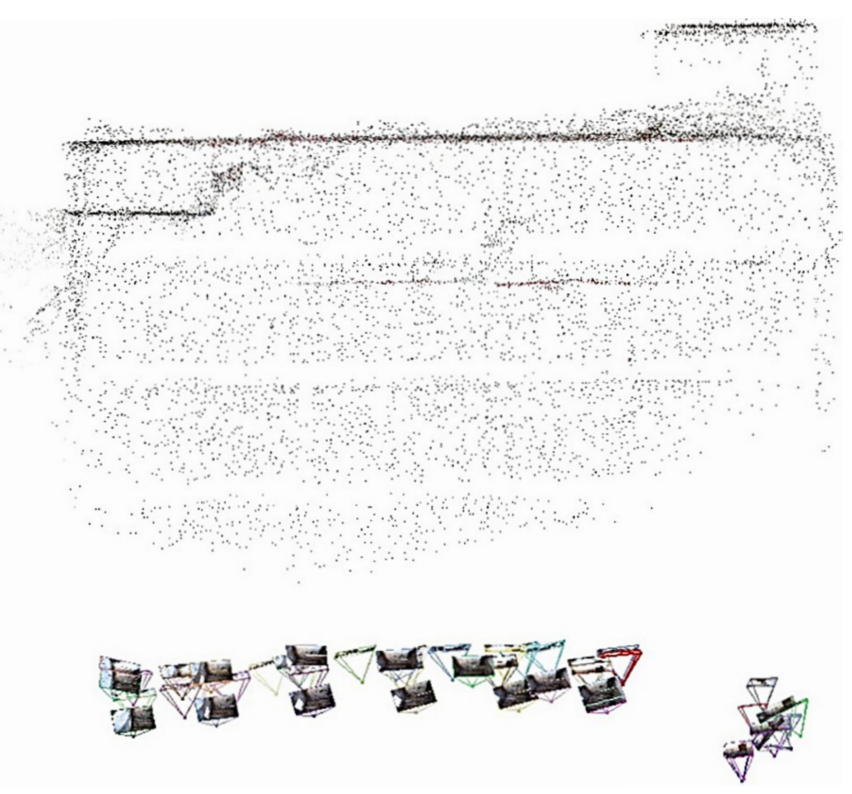

Figure 1: Camera shot locations. 


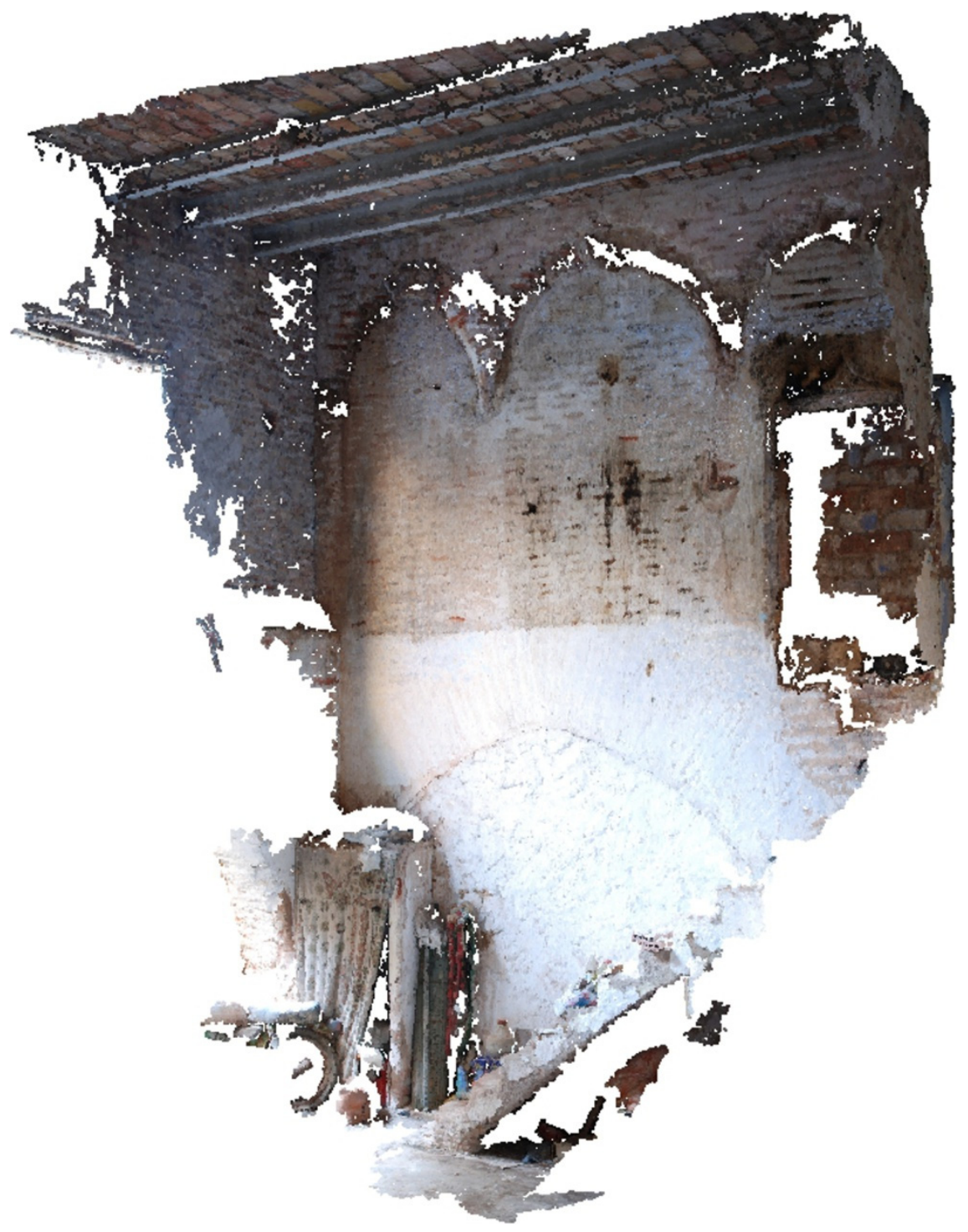

Figure 2: Coloured point cloud.

In addition, the resolution of each photograph depends on the values used for each different photographic parameter, such as diaphragm opening, ISO sensitivity and shutter speed.

These parameters depend on the kind of camera used. For digital camera Nikon D-80, in manual mode, we can adjust an ISO/100 value with an aperture from F/11 to $\mathrm{F} / 16$. After the camera is placed in front of the object, automatic mode is used 
to focus on the object and the camera is then switched to manual mode, so that focal length does not change. Finally, the rate of shot is selected in order to produce a slightly overexposed photograph, with the sensor providing the best possible information.

The use of a tripod is advisable to achieve better results as the shooting speed will be slow and freehand camera movement decreases the sharpness of images. In this regard, trigger cables are extremely useful as is delaying the shot to avoid camera movements which are detrimental to photogrammetry.

It is also advisable to lower the mirror beforehand, as DSLR cameras lower it automatically when the photograph is taken, but there is usually an option that can be activated to lower it in advance and not immediately before the shot. All this aims to avoid any camera movement so that the pictures are as sharp as possible.

\subsection{Data processing}

In photogrammetry, data must be processed with specific software in order to get the results. This allows us to establish accurate results, because the more complete the work on the data, the better defined the result, given that the amount of points defining virtual models generated is determined when processing pictures rather than when taking them. As a result, it will be possible to generate several threedimensional models of the object to be analysed in different resolutions, with no need for additional records.

This work can be summed up in three stages.

1. Processing of the images in RAW format. This first step allows us to obtain better data than that provided by the JPG format. Some aspects that we can control are balance of whites, exposure, contrast, saturation, and calibration of the different colour channels. RawTherapee [6] version 4.0.12.60, a specific free software for processing RAW files and converting them to JPEG or TIFF, was used for the purpose of adjustments.

2. The control points and the dense point clouds are obtained from the JPG images processed in advance. This is done by running VisualSFM [7], a program that composes a set of these images in a $3 \mathrm{D}$ model, refining the model into a dense points cloud as a ply file which stores a denser points cloud, each with position, colour and normal data. (Visual SFM by the software engineer Changchang $\mathrm{Wu}$ is a Visual 3D reconstruction system that integrates SiftGPU and Multi-core Bundle Adjustment.)

3. Meshing is the next step used to cover the whole 3D model of the constructed element. A triangulated irregular network (TIN) following a Delaunay triangulation is used to cover the whole area.

4. Photo-realistic texturing. To obtain a completed 3D model we need to add the information on texture from images to the object model produced from its meshes. This allows us to create a photo-realistic model (Yastikli [8]).

For points 3 and 4 we used the Meshlab [9] program which allows us to produce a textured, clean, high-rise mesh. (Meshlab is a tool developed with the support of the 3D-CoForm project.) The results of this step are found in a .obj file and a .png file. 


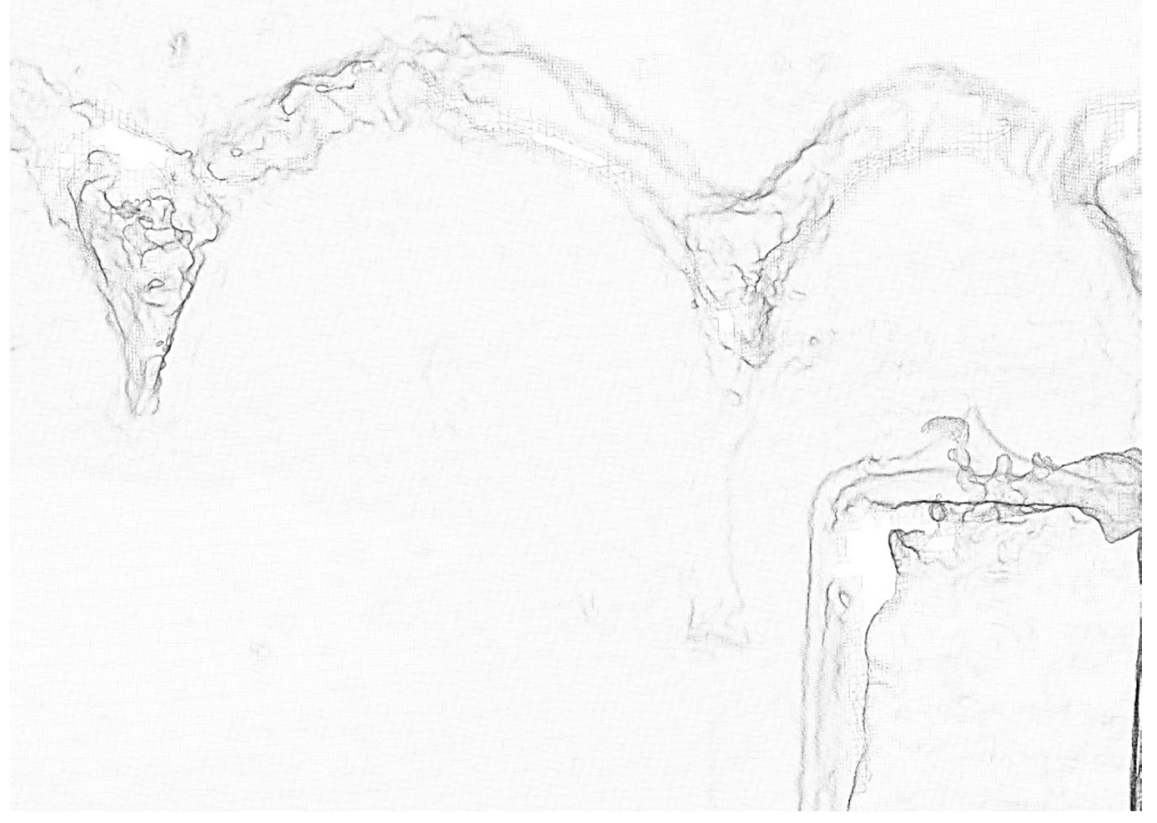

Figure 3: Close-up view of wire-frame 3D model.

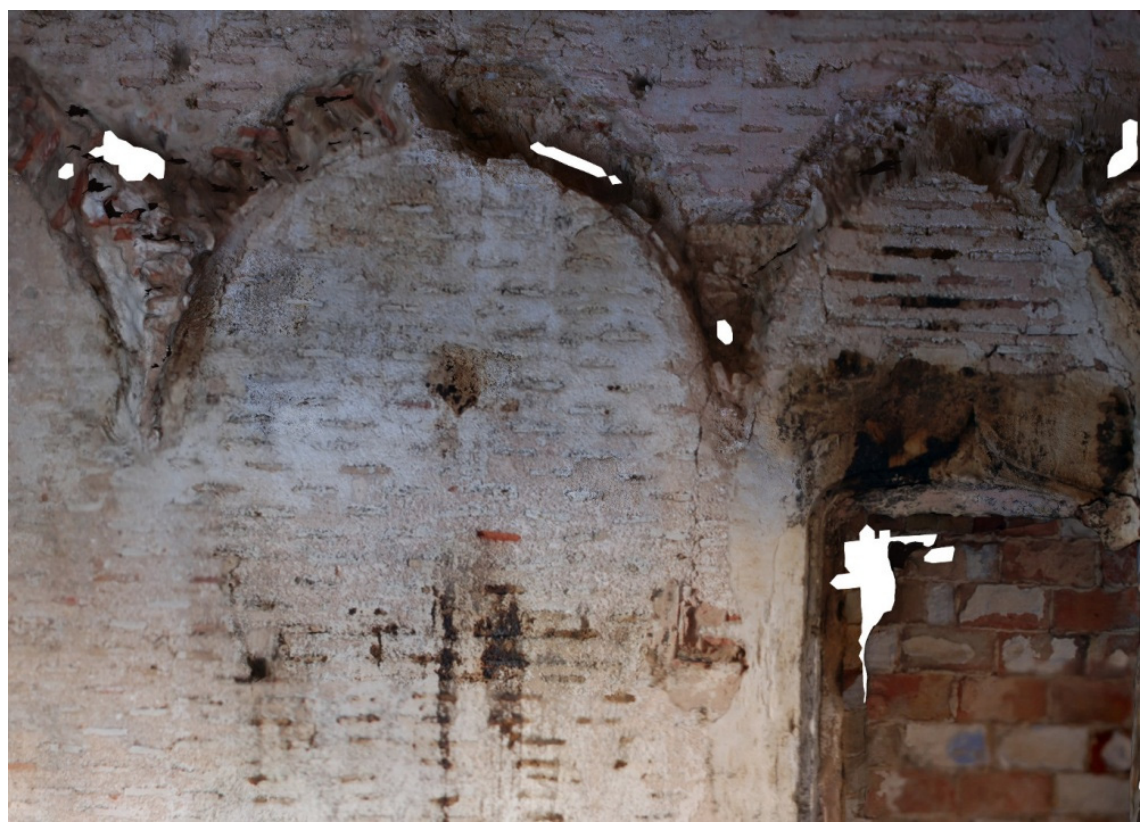

Figure 4: Photo-realistic view. 


\section{Conclusions}

The results show that it is possible to build highly accurate $3 \mathrm{D}$ models with conventional cameras (with no need for heavy or expensive equipment) while being able to add high quality textures of the constructed element from the most convenient positions around it.

The photogrammetric approach based on imagery acquired with digital cameras can be considered a serious alternative to other much more expensive approaches using mostly range-based devices such as terrestrial laser scanners. It can be successfully used to collect data from archaeological remains and architectural heritage.

In addition, textured surfaces generated using photogrammetry are the best tool to study architectural pathologies because the data are reported precisely thanks to lightness values of the photographed surface. As a result, we not only get a rigorous geometry from the building, but all the information contained in the pictures: colours, textures, materials, states of degradation.

\section{Acknowledgements}

To Vicent Burguera for management, classification and analysis of the documents preserved in the Archaeological Museum of Oliva, and especially for his expert advice in onsite visits and data collection.

To Rafael Soler Verdú for his reasoned observations on the palace.

This activity is included in the research project "Bóvedas aristadas en el gótico valenciano: recreación virtual a partir del estudio geométrico-constructivo para su difusión en las redes de comunicación" (Reference: GV/2013/137). Funded by the Generalitat Valenciana, as R \& D for emerging groups, 2013.

\section{References}

[1] Viollet-le-Duc. Reasoned Dictionary of French Architecture 11th-16th Century (1854-1868), and Reasoned Dictionary of the French Bank from the Carlovingians to the Renaissance (1858-1875).

[2] Associacio Cultural Centelles I Riu-Sec (ACCRS). Palau dels Centelles RiuSec d'Oliva. Recull grafic I documental. Oliva. 1997.

[3] Muller, Priscilla E. A la recerca del palau. In Cabdells: research journal of Cultural Asociation Centelles i Riusech, num. 1. Oliva 1999.

[4] Lerma García, J.L., Fotogrametría moderna: analítica y digital. Polytechnic University of Valencia. 2002.

[5] Almagro Gorbea, A., Levantamiento arquitectónico, Granada. 2004.

[6] RawTherapee 4.0.12. User Manual. http://rawpedia.rawtherapee.com/

[7] http://ccwu.me/vsfm/

[8] Yastikli, N., Documentation of cultural heritage using digital photogrammetry and laser scanning, Journal of Cultural Heritage, no 8. Italy 2007.

[9] http://meshlab.sourceforge.net/ 